collaboration with the United States remains. Negotations are being carried on by governments, but the authority is hoping for a decision by the end of the year.

For the time being at least, the UKAEA takes the view that several countries (the United Kingdom included) have carried through the development of liquid-sodium fast reactors to the point at which commercial exploitation is possible. The objective of joining the Super-Phenix construction project (in which West Germany and Italy are already collaborating) would be to obtain the benefits that would flow from a joint plan for the exploitation of fast reactor technology in Europe, no doubt with agreements on "who builds what" as in the European collaborative aircraft projects.

Collaboration on Super-Phénix seems to have been made attractive by (among other things) a realistic appraisal of when it would be possible to build a commercial fast reactor in the United Kingdom. With the commitment (by the British government) to a public inquiry on the building of a first pressurized water reactor (PWR) by the Central Electricity Generating Board, and the shortage of qualified staff to carry out the necessary safety studies, the promised public inquiry on a commercial fast reactor could not begin until early 1985. Although a favourable outcome would allow construction to start towards the end of that year, the authority's fast reactor engineers will plainly have to kick their heels for quite a while if plans for collaboration come to nothing.

What does happen is for the British government to decide. Sir John Hill, chairman of the UKAEA, said this week that he looked for a commitment to the principle that fast reactors would be a primary source of energy in the next century, for a commitment (by the government) to a programme of fast reactor construction in the United Kingdom and for a decision about whether fast reactor development should be carried out in collaboration or otherwise. These questions, on the British government's plate since last December, may be settled by the end of the year.

One stumbling block will clearly be the cost to the British government of joining the European collaboration. According to Sir John, the French asking price is cal-

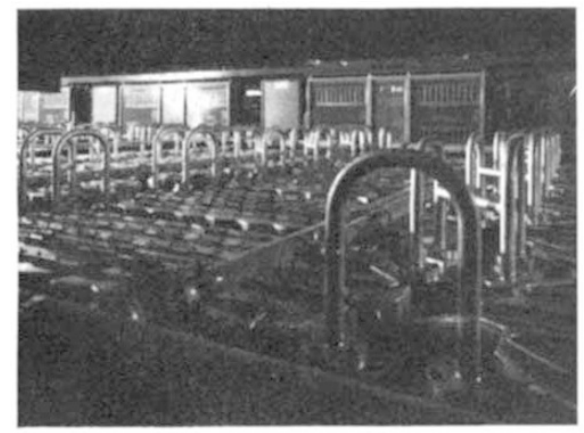

Uranium enrichment by centrifuges culated as 10 per cent of the estimated extra cost of Super-Phénix compared with a PWR of the same generating capacity, and works out as roughly $£ 50$ million. Sir John was, however, at pains to emphasize that negotiations with the French are still under way. No doubt the prospect of collaboration with the United States is being used as a counter in these negotiations, given the uncertainty about the American fast reactor programme.

For the rest, the UKAEA appears to be in robust, almost rude, health. The pilotscale version of the advanced gas cooled reactor, which has been operating at Windscale since 1962, will cease to generate electricity next March and will afterwards be used for a series of tests of the safety of the design before being decommissioned. The AEA is plainly pleased with its new rapport with the British government - Sir John Hill this week contrasted its performance with that of other governments (mentioning Austria in particular).

The authority is also more aggressive about its safety record. Sir John says that he has written to the $\mathrm{BBC}$ to protest that the "public was badly misled" by the Panorama television programme on Windscale (Nature, 11 September), but acknowledges that, at Windscale, the authority might with advantage have started replacing some of its outmoded plant ten years ago (Nature, 7 August). Earlier this week, he was also regretting that "opposition by determined groups of people... . exploiting ignorance and fear" has retarded the development and exploitation of nuclear power in many of the countries in which it is needed.

\section{Pakistan uranium}

\section{Going ahead alone}

\section{Karachi}

Pakistan seems to have taken a big step towards meeting its most urgent needs in the field of nuclear power production. After a closure of more than a year, the Karachi Nuclear Power Plant (KANUPP) has once again started producing nuclear electricity. KANUPP had to close down in mid-1979 after Canada - the supplier unilaterally stopped supply of fuel and essential parts as a result of a dispute over Pakistan's bid to acquire a nuclear reprocessing plant from France.

The re-starting of KANUPP, a heavywater reactor with a gross output of 137 $\mathrm{MW}$, has been made possible by the fabrication of fuel bundles and some essential spare parts in Pakistan. The uranium has been mined locally, in the northern Dera Ghazi Khan District. There are believed to be ample reserves of uranium in Dera Ghazi Khan; preliminary investigations in the late 1960 s revealed a reserve of at least 100,000 tons. The chairman of the Pakistan Atomic Energy Commission (PAEC), Mr Munir Ahmad Khan, is categorical in emphasizing that the fuel bundles for KANUPP had been

fabricated from locally mined ore.

Indigenous fuel fabrication has been on the cards since 1973, when Canada undertook to build a fabrication plant. Since the dispute with Canada in 1976, PAEC has designed and built a fuel fabrication plant at Chashma where the fuel bundless for KANUPP were fabricated.

Although the development of nuclear power has been in the melting pot for the past couple of years, the country now appears to be out of the woods. KANUPP, the only nuclear power plant in the country, has re-started. Another nuclear power plant of $600 \mathrm{MW}$ output, to be installed at Chashma in the early 1980s, has once again been approved.

The chairman of PAEC says that consultants for the Chashma reactor project are to be appointed soon, after which bids for building the reactor will be invited. The cost of the reactor, he says, will be about $\$ 800$ million, compared with the original estimate of $\$ 600$ million.

The Chashma reactor, unlike KANUPP, is likely to use slightly enriched uranium fuel. The chairman of the commission, at a recent press conference, declined to comment on the development of enrichment facilities in Pakestan, saying that any utterace would be misinterpreted.

The President of Pakistan, General Ziaul-Haq, is not, however, so diffident. $\mathrm{He}$ has declared that Pakistan has embarked on research on enrichment of uranium for peaceful purposes and to attain selfreliance.

Questions of the so-called "Islamic bomb" apart, there are good reasons to believe that Pakistan has been influenced on enrichment policy by the KANUPP troubles, and that it is now determined to be self-sufficient in whatever nuclear fuel its reactors need.

The search for self-sufficiency in enrichment may also be influenced by what is happening in the Middle East. The planners in Pakistan may have their eyes on the lucrative market for enriched fuel that may exist if Middle Eastern states install enriched uranium reactors of the types now being offered for sale. The planners seem chiefly interested in the centrifuge technology, which is less capital-intensive than the diffusion technology and which consumes less power.

Azim Kidwai

\section{US science policy}

\section{Press under pressure}

\section{Washington}

The Office of Science and Technology Policy (OSTP, prop Dr Frank Press) has been sharply criticized in a report from the General Accounting Office (GAO). The essence of the criticism, resisted by $\mathrm{Dr}$ Press, is well expressed by the subtitle of the report, "Adaptation to a President's operating styles may conflict with con- 
gressionally-mandated assignments',

The GAO is the investigative arm of Congress, and the report, published in Washington last week, was commissioned by Senator Adlai Stevenson, chairman of the Senate Commerce Committee's science, technology and space subcommittee. The GAO was asked to comment on how well OSTP was carrying out the legislative mandate that had been placed on it. OSTP was reestablished by Congress in 1976 after having been disbanded by President Nixon four years earlier.

The general conclusion of the GAO report is that OSTP has operated effectively in many areas. But by seeking primarily to influence decision-making within the existing policy frameworks laid down by the White House, it has failed to provide sufficient independent leadership, as envisaged in the legislation, in laying out a broad national strategy for science and technology.

Dr Frank Press, director of OSTP and the President's Science Advisor, denies that his office has failed to fulfil its mandate. In a letter to the GAO he disputes the various charges made in the GAO report and claims that dealing with strategic planning issues through particular topics and areas has been the most sensible approach.

Two particular aspects of OSTP's activities were singled out by $\mathrm{Mr}$ Stevenson for the GAO's attention. The first was the question of how far OSTP had studied various issues related to the federal organization and management of science and technology policy listed explicitly in the 1976 Act.

Here the report says that many of OSTP's actions have addressed the issues defined, some extensively, such as interactions with the Office of Management and Budget over budget decisions, and relationships with other federal agencies such as the National Science Foundation.

It also points out specific requirements which have not been met, such as the provision of a regular report to Congress on the state of science and technology. The GAO quotes the opinion of OSTP staff that broad, comprehensive reports are less useful than reports and actions addressing specific current problems.

However, it is in response to $\mathrm{Mr}$ Stevenson's second question that the GAO makes it most critical comments and OSTP has reacted most sharply. This is the extent to which OSTP has been involved in strategic planning for US science and technology, and the constraints under which such planning has been conducted.

As GAO admits, the concept of strategic planning is difficult to define in the context of the decentralized and pluralistic market economy of the United States. But two ways in which science and technology are important to planning efforts are identified, first in their intrinsic role in almost all policy issues and second in their increasing importance to society in their own right.

The GAO says that although OSTP staff attempt to give strategic perspective to considerations of topical or "mission" issues, such as energy or space, they believe that it is not feasible to do more comprehensive strategic planning while remaining effective within the Office of the President. OSTP therefore seldom studies the relationships of issues in the whole context of science and technology, the report says.

It characterizes this as largely a question of operating style. OSTP staff, says the GAO, "see themselves as an active agent of change within the system", and feel that the office as a whole must respect the norms of the system, an attitude which the GAO says directly affects their ability to generate new issues or advocate change.

OSTP officials defend this strategy. They point out, for example, that apart from the advice offered on specific issues such as the reorganization of energy research or budget support for basic science, OSTP does not have any independent control over the policy-making process. And efforts at painting broadbrush policies might produce little result.

In his letter to the GAO, Dr Press comments that OSTP has taken what he calls a "sensible" course in its approach to strategic issues and that "we do not believe that our effort to focus policy development has been constraining. Rather it has enabled us to address policy issues on a manageable basis".

He also reacts to the GAO's complaint that OSTP has no formal mechanism for establishing a broad agenda for itself by replying that this could be limited by the need for confidentiality at critical junctures in the policy process, and that "no one group is likely to have the breadth of view to encompass the ever-increasing span of science and technology".

The charges made in the GAO report have been made in more piecemeal fashion from other directions in the past. OSTP has tended to dismiss many of these criticisms as reflecting a misinterpretation of the complexity of its role, and a lack of recognition of the constraints under which it has to operate.

In the short term the GAO report is not likely to have much effect. With less than four months of the current administration left, there is little pressure from the White House or OSTP for a change in policy; and Dr Press has made it clear that he is unlikely to stay on for another term.

More significant will be the role of the report in discussions over Dr Press's successor. Several members of Congress who have previously expressed similar conclusions - and are likely to do so again at a Senate hearing on the report, scheduled to take place on Friday - feel that this may be the most effective way to make their opinions felt.

David Dickson

\section{Smallpox inquiry Union in dispute}

The repercussions of the smallpox accident at the Department of Medical Microbiology of the University of Birmingham, which led in 1978 to the death of Mrs Janet Parker, a technician in the department, were revived last week by the Association of Technical and Managerial Staffs (ASTMS). The union, which had been hoping to give evidence at the postponed inquest on Mrs Parker's death, due to reopen on Monday this week, has criticized the quality of the scientific evidence given at the earlier court case in which the University of Birmingham successfully defended itself against a prosecution brought by the Health and Safety Executive. The jury at the inquest gave a verdict of death by misadventure, rejecting the alternative of criminal negligence.

The ASTMS argument centres largely around the evidence given at the court proceedings by Professor Kevin McCarthy of the University of Liverpool, called by the University of Birmingham as an expert witness. His evidence was relevant because the official inquiry into the affair, conducted by a committee under Professor R.A. Shooter, concluded that Mrs Parker was most likely to have been infected with smallpox as a result of airborne transmission of the virus or, alternatively, by personal contact.

The import of McCarthy's evidence was that the procedures used in the smallpox laboratory at Birmingham were unlikely to have led to the production of aerosol contamination. To this end, he told the magistrates' court, he had himself carried out a series of experiments to assess the risk of aerosol production by procedures used in the smallpox laboratory. One of these involved the use of a water pump for actuating a pipette used for withdrawing supernatant fluid from Petri dishes in which smallpox virus had been cultivated. The pump was separated from the pipette by two flasks containing formalin.

Professor McCarthy's simulation of this equipment used the bacterium Escherichia coli rather than virus particles. On the basis of his results, he calculated that the chance of smallpox virus escaping in aerosol form would have been so small that one particle would get out once in 2,000 years.

ASTMS takes Professor McCarthy to task on the grounds that the simulation was not realistic. In practice, the ASTMS report says, the pipette would have been withdrawn from Petri dishes at frequent intervals, during which aerosol particles would be carried into the stream of water in the water pump and released into the laboratory by splashing.

The ASTMS document says that Professor McCarthy's evidence "tells us little except that he is a reasonably competent tchnician but does not really 